\title{
Transfer of Streptococcus adjacens and Streptococcus defectivus to Abiotrophia gen. nov. as Abiotrophia adiacens comb. nov. and Abiotrophia defectiva comb. nov., Respectively
}

\author{
YOSHIAKI KAWAMURA, * XIAO-GANG HOU, FERDOUSI SULTANA, SHUJUN LIU, \\ HIROYUKI YAMAMOTO, AND TAKAYUKI EZAKI \\ Department of Microbiology, Gifu University School of Medicine, \\ 40 Tsukasa-machi, Gifu 500, Japan
}

\begin{abstract}
We performed this study to determine the 16S rRNA sequences of the type strains of Streptococcus adjacens and Streptococcus defectivus and to calculate the phylogenetic distances between these two nutritionally variant streptococci (NVS) and other members of the genus Streptococcus. S. adjacens and $S$. defectivus belonged to one cluster, but this cluster was not closely related to other streptococcal species. A comparative analysis of the sequences of these organisms and other low-G+C-content gram-positive bacteria revealed that the two NVS species formed a distinct cluster and were only remotely related to the Aerococcus and Carnobacterium clusters. The highest level of homology (93.7\%) was found between $S$. adjacens and Carnobacterium divergens. Carnobacterium species have meso-diaminopimelic acid in their cell walls, but $\boldsymbol{S}$. adjacens and $\boldsymbol{S}$. defectivus have L-lysine as the diamino acid at position 3 in their peptidoglycan tetrapeptides. On the basis of our findings and the results of previous phenotypic studies, we propose that the NVS species should be placed in a new genus, the genus Abiotrophia, as Abiotrophia adiacens comb. nov. and Abiotrophia defectiva comb. nov.
\end{abstract}

In 1961, Frenkel and Hirsch (13) described a new type of gram-positive bacteria that exhibited satellitism around colonies of other bacteria, and they identified this new type of bacteria as streptococci. Since then, many names have been given to these bacteria. These names include satelliting streptococci (20), thiol-requiring streptococci (6), vitamin $\mathrm{B}_{6^{-}}$or pyridoxal-dependent streptococci $(4,21)$, symbiotic streptococci (14), and nutritionally variant streptococci (NVS) $(10,11$, $16)$; the latter has been the most popular name. Many researchers have investigated the growth $(4,21)$, morphology $(2)$, biochemical traits $(3,10)$, fermentation products $(5)$, and cell wall components (24) of these organisms. On the basis of the resulting data it has been suggested that these taxa are closely related to the genus Streptococcus and belong to Streptococcus mitis or "Streptococcus mitior" $(4,15)$. In 1989, Bouvet et al. (1) performed a DNA-DNA hybridization study with NVS strains and Streptococcus species and validly named the NVS Streptococcus adjacens and Streptococcus defectivus. This is the only study in which the genetic relationships of these organisms were clarified. However, the data of Bouvet et al. revealed that Streptococcus adjacens and Streptococcus defectivus exhibited levels of similarity of less than $10 \%$ with all other members of the genus Streptococcus and exhibited levels of similarity of less than $6 \%$ with Streptococcus mitis, the most closely related species as determined by a phenotypic study. The genetic relationship between the NVS species and the other members of the genus Streptococcus remained uncertain.

During our study to determine phylogenetic relationships among members of the genus Streptococcus by using 16S rRNA sequences, we noticed that the two NVS type strains were not related to any species belonging to the genus Streptococcus. We compared the NVS $16 \mathrm{~S}$ rRNA sequences with the sequences of other species which have low $\mathrm{G}+\mathrm{C}$ contents, determined the phylogenetic positions of the NVS, and decided to create a new genus for the two NVS species.

* Corresponding author. Phone: 81-58-267-2240. Fax: 81-58-2670156. Electronic mail address: kawamura@cc.gifu-u.ac.jp.

\section{MATERIALS AND METHODS}

Bacterial strains. The strains which we used are the type strains of Streptococcus adjacens (GIFU 12706 [ = ATCC 49175]) and Streptococcus defectivus (GIFU 12707 [= ATCC 49176]). These strains were grown on Columbia blood agar base (Difco) supplemented with $5 \%$ defibrinated sheep blood (CBA) and $0.01 \%$ L-cysteine (Sigma Chemical Co., St. Louis, Mo.) at $37^{\circ} \mathrm{C}$ under aerobic conditions. To confirm the purity and the nutritional requirements, the following three tests were performed: (i) a satellite test on CBA with Staphylococcus epidermidis GIFU9123 ${ }^{\mathrm{T}}$ ( $\mathrm{T}=$ type strain), (ii) a growth test in Todd-Hewitt broth (THB) (Difco Laboratories, Detroit, Mich.) containing or lacking $0.001 \%$ pyridoxal hydrochloride (E. Merck, Darmstadt, Germany) or $0.01 \%$ L-cysteine, and (iii) a biochemical test in which we used API-Strep preparations (BioMerieux, Marcy l'Etoile, France).

Analysis of diaminopimelic acid. The diaminopimelic acid was analyzed by the thin-layer chromatography method (19). Briefly, $50 \mathrm{mg}$ (wet weight) of cells was harvested from THB containing pyridoxal hydrochloride, and the cells were hydrolyzed with $1 \mathrm{ml}$ of $6 \mathrm{~N} \mathrm{HCl}$ at $100^{\circ} \mathrm{C}$ for $18 \mathrm{~h}$. The hydrolysates were filtered and dried with a rotary evaporator. Each sample was applied to a cellulose thin-layer chromatography plate (catalog no. 5552; Merck). Methanol-water-6 N $\mathrm{HCl}$-pyridine $(40: 13: 2: 5, \mathrm{vol} / \mathrm{vol} / \mathrm{vol} / \mathrm{vol})$ was used as the developing solution. After the plate was developed, the spots were visualized by spraying it with a $0.2 \%$ ninhydrin solution. DL-Diaminopimelic acid (Sigma) and cell wall hydrolysate from Carnobacterium funditum IFO 15549 (12) were used as the standard and reference preparations, respectively.

16S rRNA gene sequence determination and analysis. The 16S rRNA genes were amplified by using the PCR method described previously (17). The sequences were determined by using the dye primer method and an automatic sequencer (model 373A; Applied Biosystems, Inc., Foster City, Calif.). The 16S rRNA sequence from position 8 to position 1392 (Escherichia coli numbering) was determined for each organism.

The sequences of the other members of the genus Streptococcus and low$\mathrm{G}+\mathrm{C}$-content gram-positive bacteria used for alignment and for calculating levels of homology were obtained from the GenBank and EMBL databases. The CLUSTAL W software originally described by Thompson et al. (23) was used to align the sequences, and phylogenetic distances were calculated by using the neighbor-joining method. An unrooted phylogenetic tree was drawn by using tree tool software.

Nucleotide sequence accession numbers. The nucleotide sequences of the $16 \mathrm{~S}$ rRNAs of Abiotrophia adiacens (Streptococcus adjacens) and Abiotrophia defectiva (Streptococcus defectivus) have been deposited in the DNA Data Bank of Japan under accession numbers D50540 and D50541, respectively.

\section{RESULTS AND DISCUSSION}

The type strains of Streptococcus adjacens and Streptococcus defectivus grew only around colonies of Staphylococcus epidermidis on CBA plates and in THB supplemented with $0.001 \%$ 


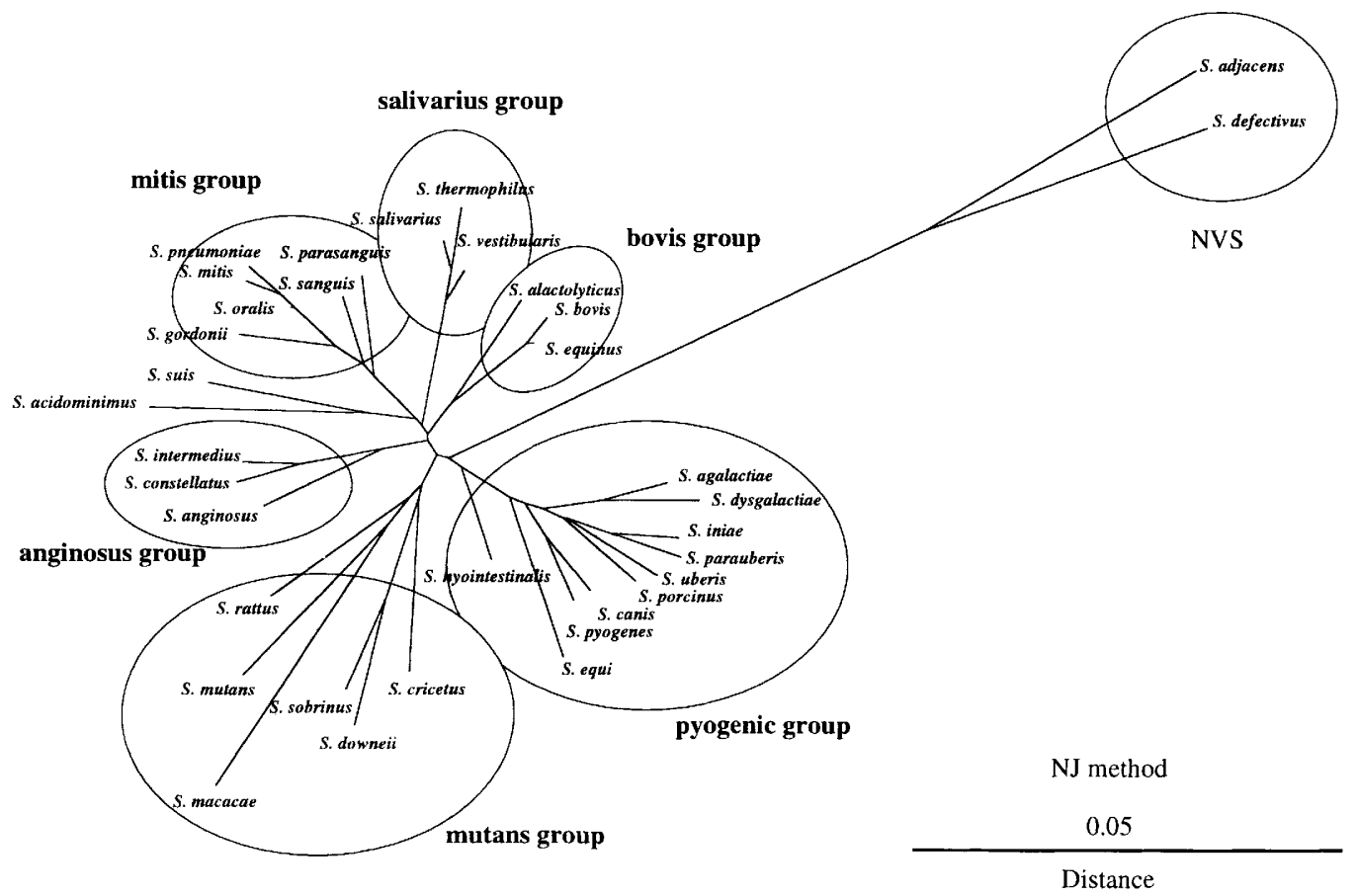

FIG. 1. Phylogenetic relationships between the two NVS species and members of the genus Streptococcus. Distances were calculated by the neighbor-joining (NJ) method.

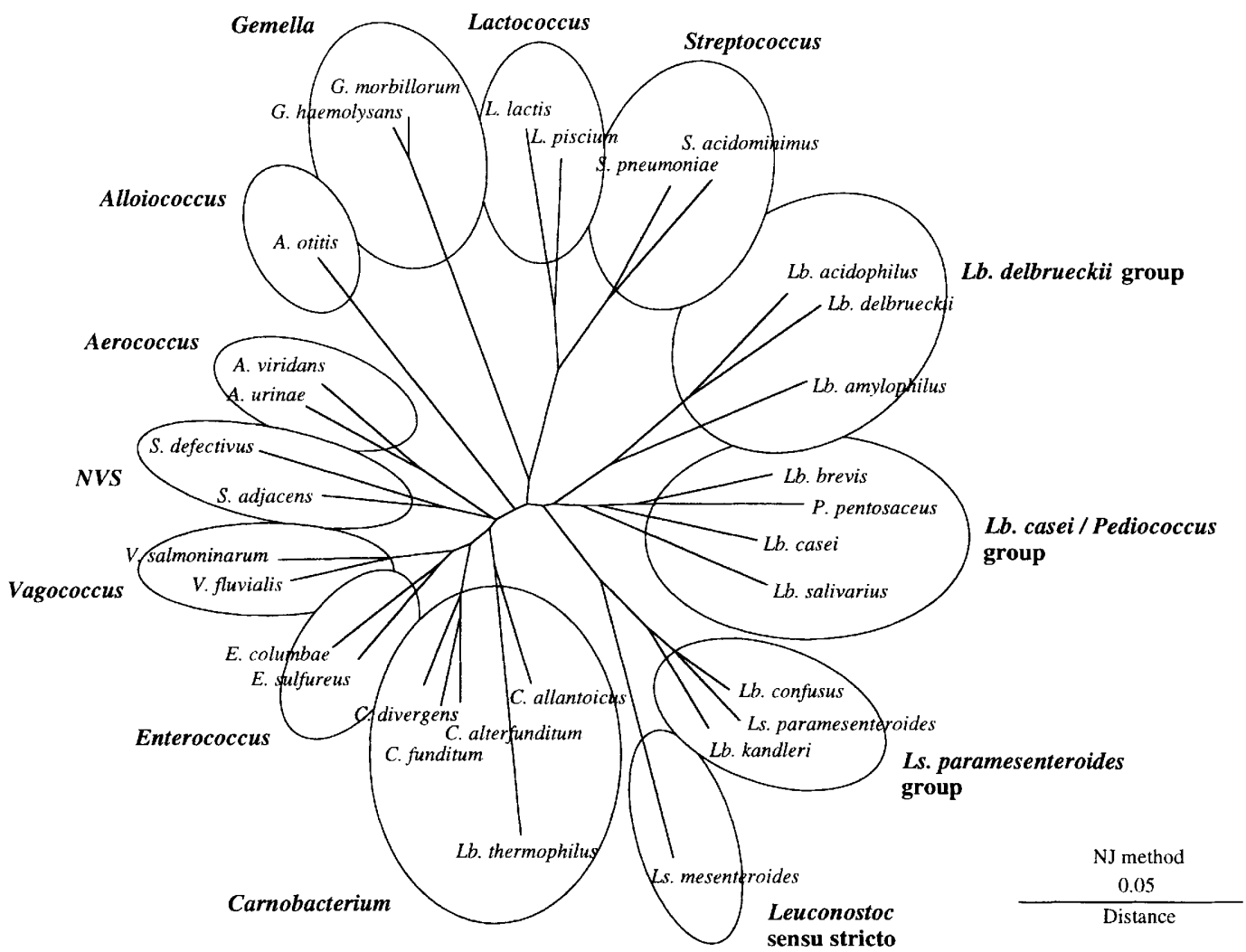

FIG. 2. Phylogenetic positions of the two NVS species and some selected low-G+C-content gram-positive bacteria. Distances were calculated by the neighborjoining (NJ) method. Lb., Lactobacillus; Ls., Leuconostoc. 
TABLE 1. Levels of 16S rRNA sequence homology among Streptococcus adjacens, Streptococcus defectivus, and some low-G $+\mathrm{C}$-content gram-positive bacteria

\begin{tabular}{|c|c|c|c|}
\hline \multirow{2}{*}{ Genus or group } & \multirow{2}{*}{ Species } & \multicolumn{2}{|c|}{$\%$ Homology with: } \\
\hline & & Streptococcus adjacens & Streptococcus defectivus \\
\hline \multirow[t]{2}{*}{ NVS } & Streptococcus adjacens & 100.0 & \\
\hline & Streptococcus defectivus & 93.0 & 100.0 \\
\hline \multirow[t]{2}{*}{ Aerococcus } & Aerococcus urinae & 91.7 & 90.6 \\
\hline & Aerococcus viridans & 91.0 & 89.5 \\
\hline Alloiococcus & Alloiococcus otitis & 88.8 & 86.8 \\
\hline \multirow[t]{5}{*}{ Carnobacterium } & Carnobacterium allantoicus & 93.3 & 90.4 \\
\hline & Carnobacterium alterfunditum & 93.1 & 90.1 \\
\hline & Carnobacterium divergens & 93.7 & 90.4 \\
\hline & Carnobacterium funditum & 93.1 & 90.1 \\
\hline & Lactobacillus thermophilus & 88.4 & 86.8 \\
\hline \multirow[t]{2}{*}{ Enterococcus } & Enterococcus columbae & 91.3 & 89.4 \\
\hline & Enterococcus sulfureus & 92.1 & 89.4 \\
\hline \multirow[t]{2}{*}{ Gemella } & Gemella haemolysans & 86.1 & 86.5 \\
\hline & Gemella morbillorum & 85.8 & 86.6 \\
\hline \multirow[t]{2}{*}{ Lactococcus } & Lactococcus lactis & 86.2 & 86.4 \\
\hline & Lactococcus piscium & 86.8 & 87.4 \\
\hline \multirow[t]{4}{*}{ Lactobacillus casei-Pediococcus group } & Lactobacillus brevis & 89.6 & 87.7 \\
\hline & Lactobacillus casei & 91.3 & 89.0 \\
\hline & Lactobacillus salivarius & 89.6 & 88.7 \\
\hline & Pediococcus pentosaceus & 89.7 & 87.8 \\
\hline \multirow[t]{3}{*}{ Lactobacillus delbrueckii group } & Lactobacillus acidophilus & 87.8 & 88.0 \\
\hline & Lactobacillus amylophilus & 87.7 & 88.0 \\
\hline & Lactobacillus delbrueckii & 87.0 & 86.7 \\
\hline \multirow[t]{3}{*}{ Leuconostoc paramesenteroides group } & Lactobacillus confusus & 88.9 & 87.4 \\
\hline & Lactobacillus kandleri & 88.8 & 86.7 \\
\hline & Leuconostoc paramesenteroides & 88.3 & 87.1 \\
\hline Leuconostoc sensu stricto & Leuconostoc mesenteroides & 86.5 & 86.3 \\
\hline \multirow{2}{*}{ Streptococcus } & Streptococcus acidominimus & 85.5 & 85.6 \\
\hline & Streptococcus pneumoniae & 86.7 & 86.5 \\
\hline \multirow[t]{2}{*}{ Vagococcus } & Vagococcus fluvialis & 91.8 & 88.6 \\
\hline & Vagococcus salmoninarum & 92.1 & 88.9 \\
\hline
\end{tabular}

pyridoxal hydrochloride and THB supplemented with $0.01 \%$ L-cysteine. Both type strains exhibited positive reactions in pyrrolidonyl arylamidase (PYR), $\beta$-glucuronidase, and leucine aminopeptidase tests, and the Streptococcus defectivus type strain also exhibited positive reactions in $\alpha$-galactosidase, $\beta$-galactosidase, trehalose fermentation, and lactose fermentation tests and weakly positive reactions in starch fermentation and acetoin production tests. All of these data are consistent with the previously described characteristics of Streptococcus adjacens and Streptococcus defectivus $(1,3)$.

The 16S rRNA gene sequences of the two NVS type strains were investigated to determine the relationships of these organisms to other members of the genus Streptococcus and to other low-G+C-content gram-positive bacteria. Data for 33 species of the genus Streptococcus were prepared, and the sequences were aligned with the sequences of the two NVS type strains.

A phylogenetic tree containing the two NVS strains and other members of the genus Streptococcus is shown in Fig. 1. In a previous study, we found that the members of the genus Streptococcus belonged to six major clusters and two loosely related species (Streptococcus suis and Streptococcus acidominimus) (17). The two NVS type strains belonged to one cluster, but this cluster was not closely related to the other six clusters, Streptococcus suis and Streptococcus acidomonimus. The most closely related species was Streptococcus hyointestinalis, but the levels of homology between this organism and Streptococcus adjacens and Streptococcus defectivus were only 88.3 and $89.2 \%$, respectively. These data demonstrated that the two NVS type strains were not closely related to any species belonging to the genus Streptococcus and should be removed from this genus.

To investigate the phylogenetic position of the NVS among the low-G+C-content gram-positive bacteria, we prepared another data set, which contained data for representative species of 49 genera (including mycoplasmas), and calculated the phylogenetic position of the NVS. Our results showed that the NVS cluster was near the Aerococcus-Vagococcus-Enterococ- 
TABLE 2. $\mathrm{G}+\mathrm{C}$ contents and peptidoglycan structures of selected genera

\begin{tabular}{|c|c|c|c|c|}
\hline \multirow{2}{*}{ Genus } & \multirow{2}{*}{$\begin{array}{c}\mathrm{G}+\mathrm{C} \text { content }(\mathrm{mol} \%) \\
(\text { method })^{a}\end{array}$} & \multicolumn{3}{|c|}{ Peptidoglycan structure } \\
\hline & & Position 3 & Crossbridge & Type $(\mathrm{s})^{h}$ \\
\hline Abiotrophia (NVS) & $37-47\left(T_{m}\right)$ & Lys & $\mathrm{Ala}_{1-2}$ & $\mathrm{~A} 3 \alpha$ \\
\hline Aerococcus & $35-40\left(T_{m}\right)$ & Lys & None (direct) & $\mathrm{A} 1 \alpha$ \\
\hline Alloiococcus & $44-45\left(T_{m}\right)$ & $\mathrm{ND}^{c}$ & ND & ND \\
\hline Carnobacterium & $33-37\left(T_{m}\right)$ & meso-DAP ${ }^{d}$ & None (direct) & $\mathrm{A} 1 \gamma$ \\
\hline Enterococcus & $37-45\left(T_{m}\right)$ & Lys & Asp, $\mathrm{Ala}_{2-3}$ & $\mathrm{~A} 4 \alpha, \mathrm{A} 3 \alpha$ \\
\hline Gemella & $32-35(\mathrm{Bd})$ & Lys & Ala $_{1-3}$ & $\mathrm{~A} 3 \alpha$ \\
\hline Lactobacillus & $32-53\left(T_{m}, \mathrm{Bd}\right)$ & Lys $^{e}$ & $\mathrm{Asp}^{e}$ & $\mathrm{~A} 4 \alpha^{e}$ \\
\hline Lactococcus & $34-43\left(T_{m}\right)$ & Lys & Asp, Ala-Gly-Ala ${ }^{e}$ & $\mathrm{~A} 4 \alpha, \mathrm{A} 3 \alpha$ \\
\hline Leuconostoc & $38-44\left(T_{m}, \mathrm{Bd}\right)$ & Lys & Ser-Ala $2, \mathrm{Ala}_{2}{ }^{e}$ & $\mathrm{~A} 3 \alpha$ \\
\hline Pediococcus & $34-42\left(T_{m}\right)$ & Lys & Ala-Asp, Ala & $\mathrm{A} 4 \alpha, \mathrm{A} 3 \alpha$ \\
\hline Streptococcus & $34-46\left(T_{m}, \mathrm{Bd}\right)$ & Lys & $\mathrm{Ala}_{1-4}$, Ala-Ser, none (direct) & $\mathrm{A} 3 \alpha, \mathrm{A} 1 \alpha$ \\
\hline Vagococcus & $33-37\left(T_{m}\right)$ & Lys & Asp & $\mathrm{A} 4 \alpha$ \\
\hline
\end{tabular}

${ }^{a} T_{m}$, thermal denaturation method; Bd, buoyant density method.

${ }^{b}$ Peptide types described by Schleifer and Kandler (22).

${ }^{c} \mathrm{ND}$, no data available.

${ }^{a}$ meso-DAP, meso-diaminopimelic acid.

e Predominant data for the genus.

cus-Carnobacterium cluster (data not shown). We then prepared a third data set, which contained data for 29 species belonging to 11 genera, including the genera Streptococcus, Aerococcus, and Carnobacterium, and other lactic acid and related bacteria to determine the exact phylogenetic position of the two NVS species. The resulting phylogenetic tree is shown in Fig. 2, and the levels of homology of Streptococcus adjacens and Streptococcus defectivus with other species are shown in Table 1.

On our phylogenetic tree, each established genus was well separated, and its members formed a distinct cluster. The members of the genera Lactobacillus, Pediococcus, and Leuconostoc were divided into four groups (the Lactobacillus delbrueckii group, the Lactobacillus casei-Pediococcus group, the Leuconostoc paramesenteroides group, and the genus Leuconostoc sensu stricto), in accordance with the results of previous studies $(7,8)$. Streptococcus adjacens and Streptococcus defectivus clearly belonged to one cluster, which was not closely related to the genus Streptococcus cluster and was loosely related to the Aerococcus cluster.

The level of homology between Streptococcus adjacens and Streptococcus defectivus sequences was $93.0 \%$. The highest levels of sequence homology to Streptococcus adjacens or Strep- tococcus defectivus were exhibited by Carnobacterium divergens (93.7\%) and Aerococcus urinae (90.6\%).

Streptococcus adjacens and Streptococcus defectivus lack diaminopimelic acid in their cell walls, while $C$. funditum cell walls contain meso-diaminopimelic acid. The cell walls of NVS strains were analyzed by van de Rijn (24), who found that the mean ratio of muramic acid to glucosamine to glutamic acid to lysine to alanine was $1.0: 1.3$ to $2.1: 1.0: 1.0: 3.3$ to 3.7 . These data indicate that L-lysine may be the diamino acid at position 3 and that alanine or alanine-alanine may be the peptide cross bridge, and the presumptive peptide type is type $\mathrm{A} 3 \alpha$ (Table 2). On the other hand, Carnobacterium species contain mesodiaminopimelic acid and have a type A1 $\gamma$ direct cross-linkage (9), whereas in Aerococcus species L-lysine is the diamino acid at position 3 and the direct cross-linkage type is type $\mathrm{A} 1 \alpha(22)$. The two NVS strains could be clearly distinguished from the genera Carnobacterium and Aerococcus on the basis of these data.

We investigated the relationships between the two NVS type strains and other members of the genus Streptococcus and the low-G+C-content gram-positive bacteria. The $16 \mathrm{~S}$ rRNA sequence data clearly demonstrated that the two NVS type

TABLE 3. Phenotypic characteristics that differentiate the genus Abiotrophia from other catalase-negative, gram-positive cocci

\begin{tabular}{|c|c|c|c|c|c|c|c|c|c|c|}
\hline \multirow{2}{*}{ Genus } & \multirow{2}{*}{ Satellitism } & \multirow{2}{*}{$\begin{array}{l}\text { Susceptibility to } \\
\text { vancomycin } \\
(30-\mu \mathrm{g} \text { disk })^{a}\end{array}$} & \multirow{2}{*}{$\begin{array}{l}\text { Gas produc- } \\
\text { tion from } \\
\text { glucose }\end{array}$} & \multirow{2}{*}{$\begin{array}{c}\text { PYR } \\
\text { activity }\end{array}$} & \multirow{2}{*}{$\begin{array}{l}\text { Leucine amino- } \\
\text { peptidase } \\
\text { activity }\end{array}$} & \multirow{2}{*}{$\begin{array}{c}\text { Growth in broth } \\
\text { containing } 6.5 \% \\
\mathrm{NaCl}\end{array}$} & \multicolumn{2}{|c|}{ Growth at: } & \multirow{2}{*}{ Motility } & \multirow{2}{*}{$\begin{array}{c}\text { Hemolysis on blood } \\
\text { agar (5\% sheep } \\
\text { blood) }\end{array}$} \\
\hline & & & & & & & $10^{\circ} \mathrm{C}$ & $45^{\circ} \mathrm{C}$ & & \\
\hline Abiotrophia & $+^{b}$ & $\mathrm{~S}$ & - & + & + & - & - & - & - & Alpha \\
\hline Aerococcus & - & $\mathrm{S}$ & - & + & - & + & - & + & - & Alpha \\
\hline Enterococcus & - & $\mathrm{S}$ & - & + & + & + & + & + & $\mathrm{v}$ & Alpha, beta, none \\
\hline Gemella & - & $\mathrm{S}$ & - & + & $\mathrm{v}$ & - & - & - & - & Alpha, none \\
\hline Lactococcus & - & $\mathrm{S}$ & - & + & + & $\mathrm{v}$ & + & $-{ }^{c}$ & - & Alpha, none \\
\hline Pediococcus & - & $\mathrm{R}$ & - & - & + & $\mathrm{v}$ & - & + & - & Alpha \\
\hline Streptococcus & - & $S$ & - & $-d$ & + & $-e$ & - & $\mathrm{v}$ & - & Alpha, beta, none \\
\hline Vagococcus & - & $\mathrm{S}$ & - & + & + & + & + & - & + & Alpha, none \\
\hline
\end{tabular}

${ }^{a} \mathrm{~S}$, susceptible; $\mathrm{R}$, resistant.

$b+$, more than $90 \%$ of the strains are positive; -, less than $10 \%$ of the strains are positive; v, variable

${ }^{c}$ Some strains grow very slowly at $45^{\circ} \mathrm{C}$.

${ }^{d}$ Streptococcus pyogenes strains exhibit PYR activity.

e Some beta-hemolytic streptococci grow in broth containing $6.5 \% \mathrm{NaCl}$. 
strains were phylogenetically distinct from the genus Streptococcus.

On the basis of previous data, including data on biochemical traits, fermentation products, and cell wall components, it has been demonstrated that the most characteristic traits of the NVS strains which distinguish these organisms from members of the genus Streptococcus are nutrient requirements, satellitism, and PYR test results. Furthermore, the NVS strains but not all other Streptococcus species require vitamin $\mathrm{B}_{6}$ or cysteine for growth. Only one exception to this was described by Bouvet et al. (2), but these authors used a special medium in their study. No NVS strains can grow properly on common commercial media for streptococci (e.g., blood agar based on Trypticase soy medium, CBA, and THB). The NVS strains exhibit satellitism on blood agar around other bacteria (e.g., Staphylococcus epidermidis). Some Haemophilus species also exhibit satellitism around staphylococci on blood agar. It is known that Haemophilus satellitism requires $\mathrm{X}$ factor (hemin) and $\mathrm{V}$ factor (NAD) and that growing staphylococci supply $\mathrm{V}$ factor (18). In the case of the NVS strains, $\mathrm{X}$ factor and V factor did not affect growth (10). The factor which is required by the NVS has yet to be determined, but sulfydryl compounds seem to be good candidates for compounds that are required for NVS strain growth $(10,13)$. This characteristic is also useful for distinguishing NVS strains from members of the genus Streptococcus. The NVS strains exhibited a positive reaction in the PYR test; on the other hand, almost all Streptococcus species except Streptococcus pyogenes had negative reactions in this test (11). Streptococcus pyogenes can be easily differentiated from the NVS strains by its beta-hemolysis on blood agar and by many different biochemical characteristics.

The 16S rRNA sequence data obtained for other low-G $+\mathrm{C}$ content gram-positive bacteria also clearly showed that the NVS species were independent and only remotely related to the genera Aerococcus and Carnobacterium, from which they differ in cell wall peptidoglycan structure.

In view of the data presented above, we propose that Streptococcus adjacens and Streptococcus defectivus should be classified in a new genus, the genus Abiotrophia, as Abiotrophia adiacens comb. nov. and Abiotrophia defectiva comb. nov., respectively.

Description of Abiotrophia gen. nov. Abiotrophia (Abi. o. tro'phi. a. G. prefix $a$-, negative (un-); G. n. bios, life; G. n. trophe, nutrition; M. L. n. Abiotrophia, life nutrition deficiency). The description below is based on data from this study and previously described studies $(1,3,5,10,24)$.

Cells are nonsporulating, nonmotile, and gram positive. Cells are mainly cocci, but pleomorphic ovoid cells, coccobacilli, and rod-shaped cells may occur in THB or CBA supplemented with pyridoxal hydrochloride or L-cysteine. Facultative anaerobes. Catalase and oxidase negative. Lactic acid is the compound that is predominantly produced during glucose fermentation. Does not produce gas from glucose. Growth does not occur at 10 and $45^{\circ} \mathrm{C}$ or in the presence of $6.5 \% \mathrm{NaCl}$. Nutritionally fastidious. No or slight growth occurs in THB or on CBA. Sulfydryl compounds $0.01 \%$ L-cysteine is usually used) or vitamin $\mathrm{B}_{6}(0.001 \%$ pyridoxal hydrochloride is usually used) is required for growth. Grows as satellite colonies adjacent to Staphylococcus epidermidis on blood agar. Alpha-hemolytic on sheep blood agar supplemented with $0.01 \%$ L-cysteine or $0.001 \%$ pyridoxal hydrochloride. PYR positive Resistant to optochin and susceptible to vancomycin. L-Lysine is the diamino acid at position 3 , and alanine or alaninealanine is the peptide cross bridge, so the presumptive peptide type is type $\mathrm{A} 3 \alpha$. The $\mathrm{G}+\mathrm{C}$ content of the DNA is 36.6 to 46.6 mol\%.
The type species of the genus Abiotrophia is Abiotrophia defectiva.

Tests that are useful for distinguishing the genus Abiotrophia from other catalase-negative, gram-positive cocci are shown in Table 3.

Descriptions of Abiotrophia adiacens comb. nov. and Abiotrophia defectiva comb. nov. The descriptions of $A$. adiacens and $A$. defectiva are the same as the descriptions given for Streptococcus adjacens and Streptococcus defectivus, respectively (1).

\section{ACKNOWLEDGMENT}

This work was supported in part by Grant-In-Aid for Scientific Research 06670287 from the Ministery of Education, Science and Culture of Japan.

\section{REFERENCES}

1. Bouvet, A., F. Grimont, and P. A. D. Grimont. 1989. Streptococcus defectivus sp. nov. and Streptococcus adjacens sp. nov., nutritionally variant streptococci from human clinical specimens. Int. J. Syst. Bacteriol. 39:290-294.

2. Bouvet, A., I. van de Rijn, and M. McCarty. 1981. Nutritionally variant streptococci from patients with endocarditis: growth parameters in a semisynthetic medium and demonstration of a chromophore. J. Bacteriol. 146: 1075-1082.

3. Bouvet, A., F. Villeroy, F. Cheng, C. Lamesch, R. Williamson, and L. Gutmann. 1985. Characterization of nutritionally variant streptococci by biochemical tests and penicillin-binding proteins. J. Clin. Microbiol. 22:10301034.

4. Carey, R. B., K. C. Gross, and R. B. Roberts. 1975. Vitamin $B_{6}$-dependent Streptococcus mitior (mitis) isolated from patients with systemic infections. J. Infect. Dis. 131:722-726.

5. Carlier, J. P., and A. Bouvet. 1989. Fermentation products of nutritionally variant streptococci: additional evidence for their classification in the genus Streptococcus. Res. Microbiol. 140:119-123.

6. Cayeux, P., J. F. Acar, and Y. A. Chabbert. 1971. Bacterial persistence in streptococcal endocarditis due to thiol-requiring mutants. J. Infect. Dis. 124:247-254.

7. Collins, M. D., R. C. Ash, M. Aguirre, J. A. E. Farrow, A. Martinez-Murcia, B. A. Phillips, A. M. Williams, and S. Wallbanks. 1991. Phylogenetic analysis of the genus Lactobacillus and related lactic acid bacteria as determined by reverse transcriptase sequencing of 16S rRNA. FEMS Microbiol. Lett. 77: $5-12$

8. Collins, M. D., R. R. Facklam, U. M. Rodrogues, and K. L. Ruoff. 1993. Phylogenetic analysis of some Aerococcus-like organisms from clinical sources: description of Helcococcus kunzi gen. nov., sp. nov. Int. J. Syst. Bacteriol. 43:425-429.

9. Collins, M. D., J. A. E. Farrow, B. A. Phillips, S. Ferusu, and D. Jones. 1987. Classification of Lactobacillus divergens, Lactobacillus piscicola, and some catalase-negative, asporogenous, rod-shaped bacteria from poultry in a new genus, Carnobacterium. Int. J. Syst. Bacteriol. 37:310-316.

10. Cooksey, R. C., F. S. Thompson, and R. R. Facklam. 1979. Physiological characterization of nutritionally variant streptococci. J. Clin. Microbiol. 10: 326-330.

11. Facklam, R. R., and J. A. Washigton II. 1991. Streptococcus and related catalase-negative gram-positive cocci, p. 238-257. In A. Balows, W. J. Hausler, Jr., K. L. Herrmann, H. D. Isenberg, and H. J. Shadomy (ed.), Manual of clinical microbiology, 5th ed. American Society for Microbiology, Washington, D.C.

12. Franzmann, P. D., P. Hopfl, N. Weiss, and B. J. Tindall. 1991. Psychrotrophic, lactic acid-producing bacteria from anoxic waters in Ace Lake, Antarctica; Carnobacterium funditum $\mathrm{sp}$. nov. and Carnobacterium alterfunditum sp. nov. Arch. Microbiol, 156:255-262.

13. Frenkel, A., and W. Hirsch. 1961. Spontancous development of $\mathrm{L}$ forms of streptococci requiring secretions of other bacteria or sulphydryl compounds for normal growth. Nature (London) 191:728-730.

14. George, R. H. 1974. The isolation of symbiotic streptococci. J. Med. Microbiol. 7:77-83.

15. Gross, K. C., M. P. Houghton, and R. B. Roberts. 1981. Evaluation of blood culture media for isolation of pyridoxal-dependent Streptococcus mitior (mitis). J. Clin. Microbiol. 14:266-272.

16. Hardie, J. M. 1986. Genus Streptococcus, p. 1043-1071. In P. H. A. Sneath, N. S. Mair, M. E. Sharpe, and J. G. Holt (ed.), Bergey's manual of systematic bacteriology, vol. 2. Williams \& Wilkins, Baltimore

17. Kawamura, Y., X. Hou, F. Sultana, H. Miura, and T. Ezaki. 1995. Determination of 16S rRNA sequences of Streptococcus mitis and Streptococcus gordonii and phylogenetic relationships among members of the genus Streptococcus. Int. J. Syst. Bacteriol. 45:406-408.

18. Kilian, M. 1991. Haemophilus, p. 463-470. In A. Balows, W. J. Hausler, Jr., 
K. L. Herrmann, H. D. Isenberg, and H. J. Shadomy (ed.), Manual of clinical microbiology, 5th ed. American Society for Microbiology, Washington, D.C.

19. Komagata, K., and K. Suzuki. 1987. Lipid and cell-wall analysis in bacterial systematics. Methods Microbiol. 19:161-207.

20. McCarthy, L. R., and E. J. Bottone. 1974. Bacteremia and endocarditis caused by satelliting streptococci. Am. J. Clin. Pathol. 61:585-591.

21. Roberts, R. B., A. G. Kriege, N. L. Schiller, and K. C. Gross. 1979. Viridans streptococcal endocarditis: the role of viridans species, including pyridoxaldependent streptococci. Rev. Infect. Dis. 1:955-966.
22. Schleifer, K. H., and O. Kandler. 1972. Peptidoglycan types of bacterial cell walls and their taxonomic implications. Bacteriol. Rev. 36:407-477.

23. Thompson, J. D., D. G. Higgins, and T. J. Gibson. 1994. CLUSTAL W: improving the sensitivity of progressive multiple sequence alignment through sequence weighing, position-specific gap penalties and weight matrix choice. Nucleic Acids Res. 22:4673-4680.

24. van de Rijn, I. 1985. Quantitative analysis of cell walls of nutritionally variant streptococci grown under various growth conditions. Infect. Immun. 49:518522 . 